\title{
Emergency evacuation simulation of commercial aircraft
}

\author{
Influence of body- and behaviour parameters
}

\author{
Andreas Gobbin $^{1}$ (1) $\cdot$ Raman Khosravi $^{2} \cdot$ Andreas Bardenhagen $^{1}$
}

Received: 24 September 2020 / Accepted: 28 January 2021

Published online: 10 March 2021

(c) The Author(s) 2021, corrected publication 2021 OPEN

\begin{abstract}
In order to receive certification approval for new products, aircraft manufacturers have to comply with the specifications regarding cabin evacuation. In case of real evacuation trials, agent-based simulation can be deployed, as they are a less cost-intensive mean of analysing passenger behaviour during the evacuation of commercial aircraft. This paper aims at examining the suitability of agent-based simulation software to reproduce passenger behaviour during evacuation processes. For this purpose, the algorithms and methods of the software PATHFINDER are introduced. Besides, the cabin of a single aisle aircraft is reconstructed in a high-density configuration using software-specific tools. A representative passenger distribution is implemented according to EASA regulations. Evacuation simulations for a single-aisle aircraft are conducted taking EASA standards into account. The effect of vital parameters such as walking speed, body dimension, conflict behaviour, collision response, acceleration time and exit allocation on evacuation times are examined. Results are discussed and examined for plausibility in order to determine whether evacuation simulations of commercial aircraft are possible using agent-based simulation software.
\end{abstract}

Keywords Evacuation simulation · Agent-based modelling $\cdot$ Human behaviour · Body characteristics $\cdot$ Conflict scenarios

\section{List of symbols}

$C_{\mathrm{g}} \quad$ Global cost factor (-)

$C_{1} \quad$ Local cost factor (-)

$C_{\text {target }}$ Total cost factor (-)

$F(x) \quad$ Functional value (-)

$G(x) \quad$ Previous cost factor (-)

$H(x) \quad$ Remaining cost factor (-)

$d_{\mathrm{t}} \quad$ Distance travelled in room (m)

$k_{\mathrm{d}} \quad$ Scaling factor for $k_{d d}(-)$

$k_{\mathrm{dd}} \quad$ Current room distance penalty (-)

$k_{\mathrm{gt}} \quad$ Global travel time cost factor (s)

$k_{\mathrm{lt}} \quad$ Current room travel time cost factor (s) $k_{\mathrm{q}} \quad$ Current room queue time cost factor (s)

$k_{\mathrm{qh}} \quad$ Is set to $1-p$ for the most recently chosen target and 1.0 for all other targets (-)

$p \quad$ Current door preference scaling factor of travel

$(-)$

$p_{\mathrm{d}} \quad$ Costs and global cost share (-)

$t_{\mathrm{lt}} \quad$ Current room travel time (s)

$t_{\mathrm{gt}} \quad$ Global travel time (s)

$t_{\mathrm{q}} \quad$ Current room queue time (s)

$A^{*} \quad$ A-star search algorithm

AFT Exit in the rear of the cabin

CD Comfort distance

The original version of this article has been revised: The funding note has been added.

$\triangle$ Andreas Gobbin, andreas.gobbin@tu-berlin.de; Raman Khosravi, ramankhosravi@yahoo.de; Andreas Bardenhagen, andreas.bardenhagen@tu-berlin.de $\mid{ }^{1}$ Chair of Aircraft Design and Aerostructures, Technische Universität Berlin, 10587 Berlin, Germany. ${ }^{2}$ Technische Universität Berlin, 10623 Berlin, Germany. 


$\begin{array}{ll}\text { CRT } & \text { Collision response time } \\ \text { CS } & \text { Certification specification } \\ \text { EASA } & \text { European Union Aviation Safety Agency } \\ \text { FWD } & \text { Exit in the front of the cabin } \\ \text { GUI } & \text { Graphical user interface } \\ \text { NTSB } & \text { National transportation safety board } \\ \text { OECD } & \begin{array}{l}\text { Organisation for economic co-operation and } \\ \text { development }\end{array} \\ \text { OWE } & \text { Over wing exit } \\ \text { PAX } & \text { Persons approximately }\end{array}$

\section{Motivation}

In addition to steadily increasing passenger numbers, air traffic is also showing success in terms of safety. Compared to the last 60 years, the frequency of fatal incidents has steadily decreased [1, p. 9 f.]. However, an analysis of 60 NTSB reports classified as survivable aircraft accidents shows that $78 \%$ of the fatalities occurred after impact. Of these, $95.4 \%$ were due to smoke inhalation and burns caused by slow and inefficient evacuation procedures. In contrast, immediate evacuation could increase survival rates by $98 \%[2$, p. 8]. This shows that rapid and successful evacuation of the passenger cabin has a significant impact on occupant safety and survival. Therefore, according to the certification requirement, it must be demonstrated that in the event of an emergency evacuation, it is possible to safely exit the aircraft within $90 \mathrm{~s}$. The exact wording of EASA CS-25.803 (c) [3] states that an aircraft with a seating capacity of more than 44 passengers must demonstrate that the maximum seating capacity, including the number of crew members, required by the operating rules for which certification is sought, can be evacuated from the aircraft to the ground within 90 s under simulated emergency conditions. Not more than half of the available emergency exits may be used in this process [3, pp. 1-APP $\mathrm{J}$-1] (Appendix J, paragraph ( $p)$ ). Compliance with this must be proven by an actual demonstration using the test criteria outlined in Appendix J of the CS-25, unless the agency determines that a combination of analysis and testing provides equivalent data that would be obtained by an actual demonstration [3] (Paragraph 25.803 (c)).

Because certification testing is associated with high health risks to the test subject $[4$, p. 5], it should be considered whether agent-based numerical evacuation simulations are a sufficient alternative to the specified test procedure. In accordance with the last paragraph of the approval paragraph CS-25.803 (c) [3], this paper aims to investigate the influence of behavioural and conflict parameters in agent-based simulation on the total evacuation time. Using agent-based simulations, it is possible to model evacuation scenarios under consideration of human behaviour. This enables an analysis of passenger behaviour in stressful situations and provides information for the safe design of passenger cabins. The results of the following considerations are intended to provide an initial approach to which data and analyses might be used to represent human behaviour in evacuation simulation.

In the last 20 years, more and more simulation models have been developed that allow to take human behaviour into account. This has shifted the focus from a pure motion simulation to an additional consideration of psychological, social and physiological factors. With regard to competition-oriented behaviour during an evacuation situation, the publication of Kirchner et al. [5] and the work on the consideration of emotions by the Autonomous Agents and Multiagent Systems Model of Toghar and Al Barghuthi [6] as well as Miyoshi [7] are mentioned as examples.

Various simulation environments are available to simulate evacuation scenarios considering human behaviour using agent-based algorithms. The three continuously developed tools EXODUS from the University of Greenwich [8], STEPS from Mott MacDonald Simulation Group [9] and PATHFINDER by Thunderhead Engineering Consultants, Inc. [10] were validated in the study by Cuesta et al. [11, p. $241 \mathrm{ff}$.]. All abovementioned tools were able to replicate real-life evacuation tests with good results, although each of the tools has individual strengths and weaknesses. It should be noted that only for the tool EXODUS an explicit extension for evacuation simulations of commercial aircraft (airEXODUS) [12] exists. When using STEPS and PATHFINDER, the modelling must be adapted to simulate aircraft evacuations. Further tools for evacuation simulation of commercial aircraft are listed in the publication by Togher and Al Barghuti [6, p. 277 f.].

This paper shows the suitability of numerical simulation for the evacuation of commercial aircraft by using the simulation software PATHFINDER from Thunderhead Engineering Consultants, Inc.

The subsequent section of this paper gives an overview of the simulation software and examines the simulation algorithms therein. Afterwards, the simulation procedure, reference model and assumptions for this study are presented. In the fourth section, the influence of body characteristics and parameters pertaining to conflict scenarios are described and the results obtained are discussed. Finally, the sensitivity of the evacuation time to variations of behavioural patterns is evaluated based on the results of the parameter study and the adequacy of the simulation software PATHFINDER is assessed. 


\section{Simulation software and algorithm}

PATHFINDER is an agent-based simulation software in which structures can be modelled by a two-dimensional navigation geometry. This navigation geometry provides the basis for the simulation of motion flows in a room. The creation is done by rooms, that are connected by doors, whereby any geometry can be replicated. The limitation of the flow rates allows an individual adaptation of the geometry as well as a realistic steering of the occupants [13]. In PATHFINDER obstacles are not shown explicitly. However, it is possible to provide free spaces in the navigation geometry where no movement simulation of occupants can be performed [10]. In order to assign individual behaviour the individual occupants, so-called profiles are used which can be defined via the GUI. This allows to define characteristics like body dimension, movement speed and conflict behaviour. Behavioural patterns are used to define various instructions for occupants. Thus, profiles and behaviours provide the possibility to classify occupants. Figure 1 shows the Graphical User Interface of PATHFINDER.

The movement of an occupant to a specific destination takes place in three steps: Path Planning, Path Generation and Path Following. A path to a specific target is created on the navigation geometry using the $A^{*}$ algorithm. The actual simulation is performed in steering-mode, which is using the method of inverse steering. For this purpose, several potential directions of motion (sample directions) are evaluated based on a cost objective function and the most cost-efficient direction is selected [10].

The results of the simulation are analysed and evaluated based on the total evacuation time, flow rates and number of passes per exit. In addition, the evacuation process can be animated and visualized, which enables an accurate analysis of conflict situations and solutions.

\subsection{Path planning}

Path Planning describes the process that determines the path to a goal. Each occupant has information about local and global targets as well as the expected waiting time. Since the shortest route does not necessarily represent the fastest route, a cost calculation is made for each occupant for the respective destinations. The principle "locally quickest" is applied in the context of Path Planning, in order to determine the fastest route to an occupant's destination. The principle is based on the assumption that an occupant has knowledge about the presence of a room's doors and the queues at these doors. Besides, an occupant knows the

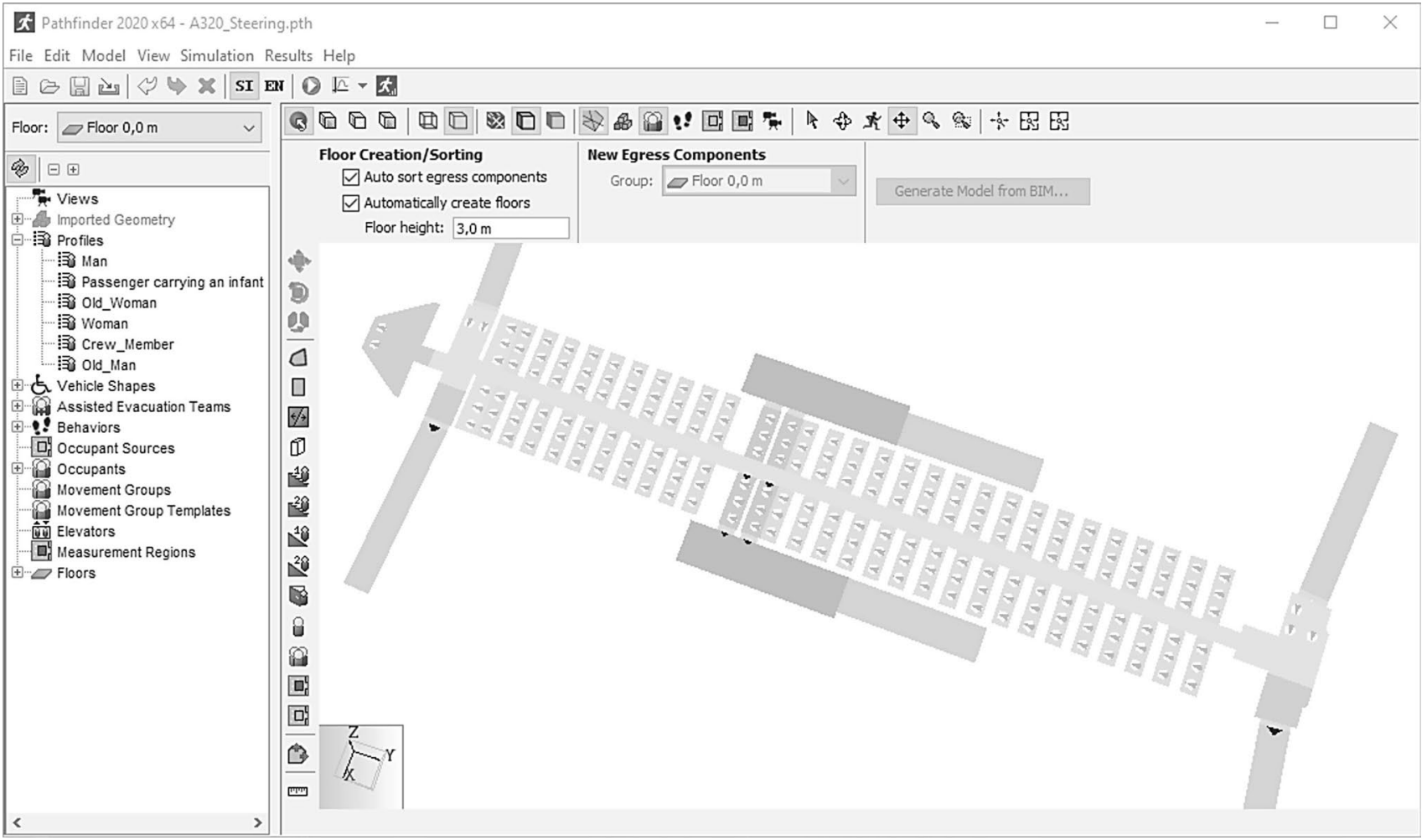

Fig. 1 Graphical User Interface of simulation software PATHFINDER 
distance from one of the doors to the occupant's ultimate destination. It is conceivable that a room has multiple local targets (e.g. multiple doors) [10, p. 18]. In this case, the least amount of time is regarded as the target function, whereby each occupant is assigned the door with the lowest cost. Based on this decision, the occupant's path to this door is generated. The total costs $C_{\text {target }}$ to a goal result from the summation of local and global costs [10, p. 19].

$C_{\text {target }}=C_{l}+C_{g}$

$C_{\text {l }}$ describes the local and $C_{g}$ the global share of the costs. The calculation of the individual cost elements is given in formulas 2 to 5 [10, p. 19].

$C_{l}=\max \left(p_{d} \cdot k_{l t} \cdot t_{l t} \mid k_{q h} \cdot k_{q} \cdot t_{q}\right)$

$C_{g}=p_{d} \cdot k_{g t} \cdot t_{g t}$

$p_{d}=e^{k_{d} \cdot d_{t}}$

$k_{d}=\frac{\log (2)}{k_{d d}}$

The factor $k_{d}$ in formula 5 is a function of the Current room distance penalty $k_{d d}$. If an occupant's distance covered in a room $d_{t}$ exceeds $k_{d d}$, the costs related to the Current room travel time $t_{l t}$ are doubled. When setting this value low, an occupant would prefer covering lower distances to lower travel times. The Current room travel time $t_{t /}$ describes the time necessary to reach a target at maximum walking speed. The Current room travel time cost factor $k_{/ t}$ is a factor used to control the significance of travel time related costs. The factor $k_{d}$ and the distance travelled in a room $d_{t}$ are inputs for the factor $p_{d}$ which influences the local $C_{l}$ and global $C_{g}$ share of the costs. The Current room queue time $t_{q}$ denotes a time estimate an occupant must wait at a door as function of the occupant's current position and the door flow rate. The Current room queue time cost factor $k_{q}$ is a factor used to control the significance of the wait-time related costs. The factor $k_{q h}$ can be calculated as a function of the current door preference $p$. The current door preference $p$ controls the frequency of an occupant switching its current goal. When set to 1 , an occupant is prevented from switching the initially chosen target, while for a value below 1 it is free to switch its local target. The Global travel time $t_{g t}$ represents the time an occupant needs to travel from a local goal (e.g. a door) to a final exit (seek goal). Similarly to the factors in formula 1 , the factor $k_{g t}$ is used to increase or decrease the significance of the associated cost parameter $t_{g t}[10$, p. 18].

\subsection{Path generation}

A path must exist for each local destination found by path planning. To find this path, an $A^{*}$ search algorithm is applied to a triangular navigation grid. Since $A^{*}$ belongs to the class of complete and optimal algorithms, an optimal solution is always found whenever a solution exists [14, p. $104 \mathrm{ff}$.]. Furthermore, due to its optimal efficiency property, there is no other algorithm that finds a faster solution using the same heuristic.

The operation of the algorithm is based on the shortest paths problem. To solve the problem, a cost calculation is made for each waypoint on the grid based on an estimation function. The heuristic applied here utilizes the linear distance between the start and destination waypoints as the lowest barrier. Since a connection between two points is never shorter than the linear distance and thus does not fall below the lowest barrier, $A^{*}$ always remains optimal in this case $[15$, p. 13 f.]. A function value $F(x)$ is allocated to each known waypoint for optimal pathfinding. This specifies how cost-intensive a path between the start and destination waypoints is, especially by taking the waypoint into consideration [14, p. 102].

$F(x)=G(x)+H(x)$

In formula (6), $G(x)$ denotes the costs incurred to reach the waypoint under consideration from the origin. $H(x)$ includes the remaining costs from the waypoint under consideration to the target waypoint, which arise from the previous heuristic.

Because of the navigation mesh in use, there is no straight path between the start and destination waypoints. To ensure this, the so-called "string pulling" method is used in addition to the $A^{*}$ algorithm [16]. Hereby, a smoothing of the path is realized, whereby a real movement pattern of the occupants is created. Figure 2 shows the generated path of an occupant based on the $A^{*}$ algorithm.

\subsection{Path following}

For following the path, a combination of inverse steering algorithm [17, p. 4 ff.] and collision handling is implemented. This allows occupants to react to obstacles and

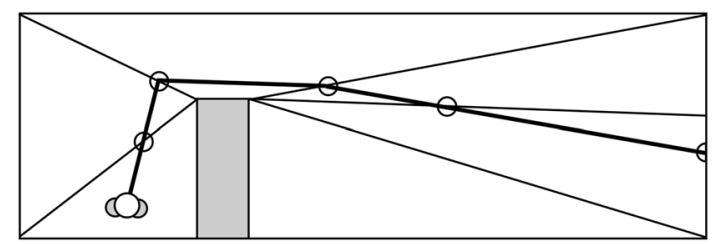

Fig. 2 Occupant's path and waypoints on the mesh [10, p. 21] 
deviate from the path to reach the actual target [10]. The inverse steering method evaluates several discrete motion directions based on the angle between the old and new path. Each new path is combined with the cost factors resulting from speed loss, acceleration- and waiting time. Finally, the path with the lowest cost factor is set as an alternative path. If the cost factor of the original path is lower in spite of the waiting time at the obstacle, the following is set on this remaining path [10].

Due to the specific steering behaviour, each occupant has an individual behaviour for collision handling, by which he/she has a direct influence on the cost evaluation during the path finding. During the movement, each occupant tries to keep a predefined behaviour with respect to distance to walls or other occupants as well as his/her speed when walking, avoiding and turning. As steering also offers the possibility of assigning specific characteristics such as age, panic behaviour and body dimensions, a realistic evacuation under consideration of human behaviour is possible. Particularly with regard to the heterogeneous age distribution within a passenger cabin, steering offers profound properties for depicting this. The advantages and the resulting steering behaviours are shown and discussed in the work of B. Schneider [18, p. 121]. The possible steering behaviours in terms of representing human behaviour and their influence on path following are also given. Due to the additional possibility of specifying acceleration times and the maximum achievable walking speeds as well as the individual adjustment of the reaction time for resolving conflicts, it is possible to simulate any class of age.

The following Fig. 3 summarizes the three steps mentioned above and their respective approaches and methods for implementation. Also given are the influence parameters of the inverse steering for description of the human behaviour. A detailed explanation of these is provided in the work of B. Schneider [18].

WHAT IS NECCESSARY TO ACHIEVE GOALS?

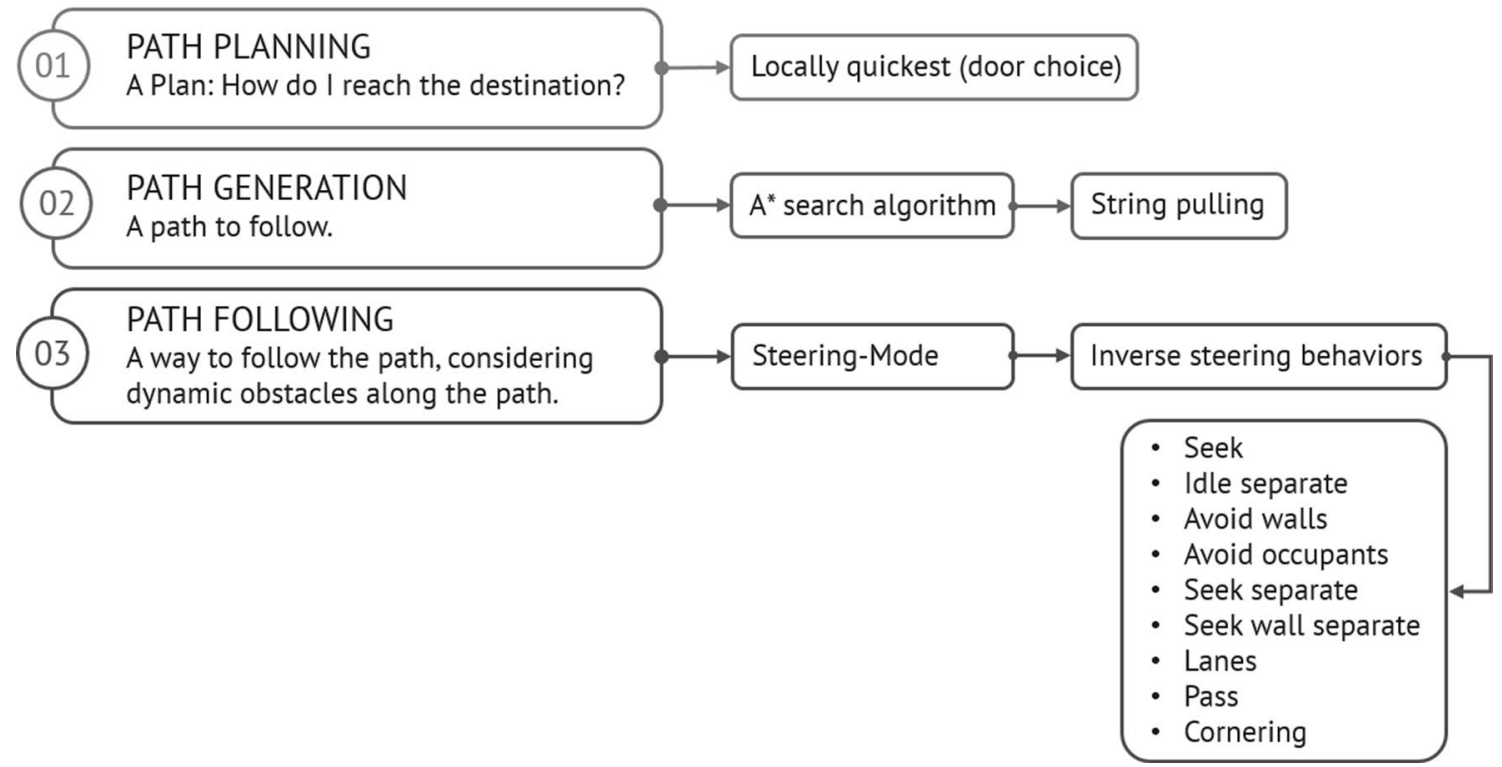

Fig. 3 Summary of the three steps path planning, -generation and -following and their respective influencing parameters, according to [19, p. 19] 


\section{Simulation procedure and reference model}

For the simulation of the evacuation process, a typical single-aisle aircraft with a maximum number of passengers of 180 and 7 crew members in high-density-configuration is modelled. The navigation geometry is implemented by rooms and doors, whereby the realistic design of seat rows, cockpit, passenger aisle and emergency slides is possible. The modelled cabin layout with emergency exits and

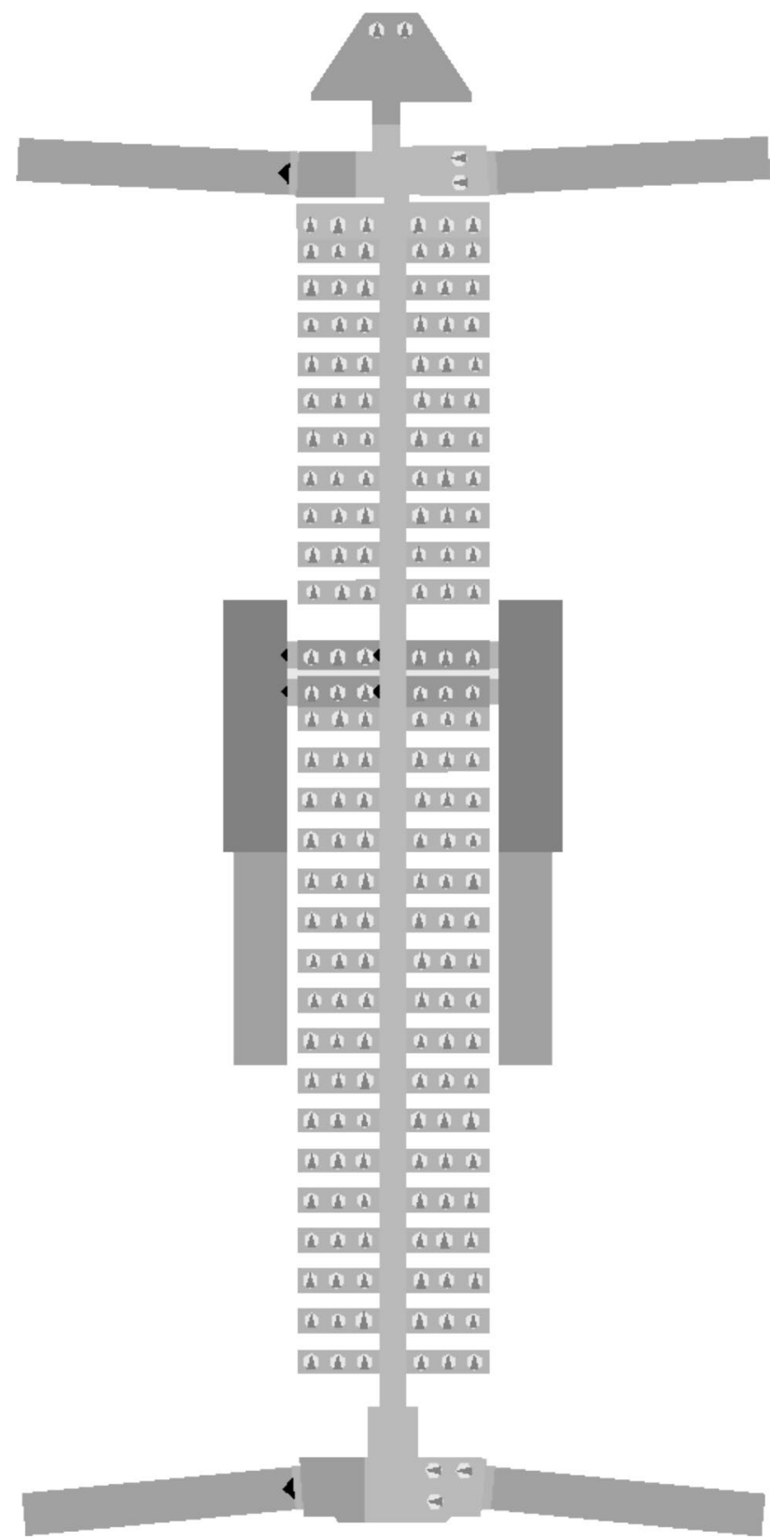

Fig. 4 Cabin of the simulation model associated emergency slides as well as positioned occupants is shown in Fig. 4.

To be able to perform the sensitivity studies for the respective body and behaviour parameters in the following chapters and to compare their significance with previously published work, the calibration of the simulation model is briefly discussed in the following section. For this purpose, 30 randomized simulations were performed under the required boundary conditions of the certification regulations [3] (Paragraph 25.803 (c)) and statistically evaluated. The percentage deviation from the manufacturer's 79.00 s specified in $[20$, p. 742$]$ resulting from the simulation tests is less than $1 \%$. The identical evacuation times at the over-wing exits 1 and 2 shown in the table are due to the use of only one emergency slide for both emergency exits. Figure 4 illustrates this problem. The following Table 1 summarizes the results of the calibration of the simulation model.

For a realistic simulation, each row of seats is modelled as a separate room, which allows reduced walking speeds in these areas. Climbing over rows of seats is not simulated. Obstacles such as galleys and lavatories are excluded from the navigation geometry by the design of free spaces.

In order to achieve a realistic simulation, specific attributes are assigned to each occupant. The specifications of EASA regarding the passenger composition are taken into account. The required passenger mix is listed below $[3, \mathrm{pp}$. 1-APP J-1] (Appendix J, paragraph (h)).

- At least $40 \%$ of passengers must be female.

- At least $35 \%$ of passengers must be over 50 years of age.

- At least $15 \%$ of passengers must be female and over 50 years of age.

- 3 persons must carry a life-size doll representing children aged 2 years or less.

For this, the profiles Man, Woman, Old Man, Old Woman and a profile representing a passenger carrying an infant of 2 years or less are defined, for which specific behaviour parameters of the respective age groups are implemented. In addition, a crew profile is defined for the crew. The

Table 1 Results of calibration of simulation mode

\begin{tabular}{llll}
\hline Emergency exit & Door count & Flow rate & Time per exit \\
\hline Exit $_{\text {FWD }}$ & 50 & $0.789 \mathrm{PAX} / \mathrm{s}$ & $75.65 \mathrm{~s}$ \\
Owe 1 & 36 & $0.614 \mathrm{PAX} / \mathrm{s}$ & $77.18 \mathrm{~s}$ \\
Owe 2 & 34 & $0.577 \mathrm{PAX} / \mathrm{s}$ & $77.18 \mathrm{~s}$ \\
Exit $_{\text {AFT }}$ & 65 & $1.042 \mathrm{PAX} / \mathrm{s}$ & $77.52 \mathrm{~s}$ \\
Evacuation time & $79.66 \mathrm{~s}(3.66 \mathrm{~s})$ & & \\
\hline
\end{tabular}




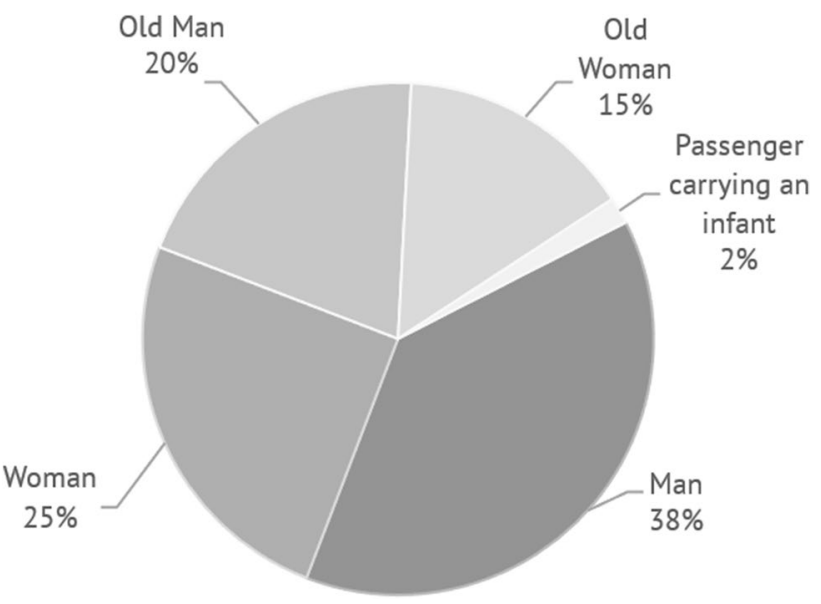

Fig. 5 Passenger percentages for evacuation simulation according to [3, pp. 1-APP J-1] (Appendix J, paragraph (h))

Table 2 Average normal movement speeds (standard deviation) [21, p. 17]

\begin{tabular}{lll}
\hline Age & Male & Female \\
\hline $20^{\prime} \mathrm{s}$ & $1.39 \mathrm{~m} / \mathrm{s}(0.153 \mathrm{~m} / \mathrm{s})$ & $1.40 \mathrm{~m} / \mathrm{s}(0.175 \mathrm{~m} / \mathrm{s})$ \\
$30^{\prime} \mathrm{s}$ & $1.45 \mathrm{~m} / \mathrm{s}(0.094 \mathrm{~m} / \mathrm{s})$ & $1.41 \mathrm{~m} / \mathrm{s}(0.127 \mathrm{~m} / \mathrm{s})$ \\
$40^{\prime} \mathrm{s}$ & $1.46 \mathrm{~m} / \mathrm{s}(0.164 \mathrm{~m} / \mathrm{s})$ & $1.39 \mathrm{~m} / \mathrm{s}(0.158 \mathrm{~m} / \mathrm{s})$ \\
$50^{\prime} \mathrm{s}$ & $1.39 \mathrm{~m} / \mathrm{s}(0.229 \mathrm{~m} / \mathrm{s})$ & $1.39 \mathrm{~m} / \mathrm{s}(0.151 \mathrm{~m} / \mathrm{s})$ \\
$60^{\prime} \mathrm{S}$ & $1.35 \mathrm{~m} / \mathrm{s}(0.205 \mathrm{~m} / \mathrm{s})$ & $1.29 \mathrm{~m} / \mathrm{s}(0.213 \mathrm{~m} / \mathrm{s})$ \\
$70^{\prime} \mathrm{s}$ & $1.33 \mathrm{~m} / \mathrm{s}(0.196 \mathrm{~m} / \mathrm{s})$ & $1.27 \mathrm{~m} / \mathrm{s}(0.211 \mathrm{~m} / \mathrm{s})$ \\
\hline
\end{tabular}

Table 3 Average maximum movement speeds (standard deviation) [21, p. 17]

\begin{tabular}{lll}
\hline Age & Male & Female \\
\hline $20 ' \mathrm{~S}$ & $2.53 \mathrm{~m} / \mathrm{s}(0.291 \mathrm{~m} / \mathrm{s})$ & $2.46 \mathrm{~m} / \mathrm{s}(0.253 \mathrm{~m} / \mathrm{s})$ \\
$30 \prime \mathrm{S}$ & $2.45 \mathrm{~m} / \mathrm{s}(0.315 \mathrm{~m} / \mathrm{s})$ & $2.34 \mathrm{~m} / \mathrm{s}(0.344 \mathrm{~m} / \mathrm{s})$ \\
$40 \prime \mathrm{S}$ & $2.46 \mathrm{~m} / \mathrm{s}(0.363 \mathrm{~m} / \mathrm{s})$ & $2.12 \mathrm{~m} / \mathrm{s}(0.275 \mathrm{~m} / \mathrm{s})$ \\
$50 \prime \mathrm{S}$ & $2.06 \mathrm{~m} / \mathrm{s}(0.448 \mathrm{~m} / \mathrm{s})$ & $2.01 \mathrm{~m} / \mathrm{s}(0.258 \mathrm{~m} / \mathrm{s})$ \\
$60 ' \mathrm{~S}$ & $1.93 \mathrm{~m} / \mathrm{s}(0.364 \mathrm{~m} / \mathrm{s})$ & $1.77 \mathrm{~m} / \mathrm{s}(0.254 \mathrm{~m} / \mathrm{s})$ \\
$70 \prime \mathrm{S}$ & $2.07 \mathrm{~m} / \mathrm{s}(0.363 \mathrm{~m} / \mathrm{s})$ & $1.74 \mathrm{~m} / \mathrm{s}(0.281 \mathrm{~m} / \mathrm{s})$
\end{tabular}

simulation results in the percentage passenger distribution shown in Fig. 5.

For the simulation model, experimentally determined walking speeds according to Bohannon [21, p. 17] are used for the respective profiles. A differentiation is made between normal and maximum motion velocities. The distribution of the average motion velocities, resulting from the experiment as well as their standard deviation, are shown in Tables 2 and 3.
Table 4 Average flow rates of exit types [25, p. 189]

Table 5 Average door flow rates of the initial reference model

\begin{tabular}{ll}
\hline Exit type & Flow rate \\
\hline Type A & 2.105 PAX/s \\
Type C & $1.067 \mathrm{PAX} / \mathrm{s}$ \\
Type I & $0.780 \mathrm{PAX} / \mathrm{s}$ \\
Type III & $0.639 \mathrm{PAX} / \mathrm{s}$ \\
\hline
\end{tabular}

\begin{tabular}{ll}
\hline Exit & Flow rate \\
\hline Exit $_{\text {FWD }}$ & $0.728 \mathrm{PAX} / \mathrm{s}$ \\
Owe 1 & $0.659 \mathrm{PAX} / \mathrm{s}$ \\
Owe 2 & $0.539 \mathrm{PAX} / \mathrm{s}$ \\
Exit $_{\text {AFT }}$ & $0.870 \mathrm{PAX} / \mathrm{s}$ \\
\hline
\end{tabular}

For the initial reference model, the normal walking speeds from Table 2 are implemented. The velocities are defined as normally distributed values for all profiles in order to ensure the highest possible randomization. With regard to body dimensions, the pre-set shoulder width of $45.58 \mathrm{~cm}$ is adopted for all profiles. A speed gradient of $160 \%$ is realized on the emergency slides. Since movement in the rows of seats is more difficult, a speed multiplier of 0.5 is simulated in this area. The settings regarding conflict management are taken from a 2017 study for the initial model [22]. In order to take the unbuckling process into account, the delay time of $2 \mathrm{~s}$ with a standard deviation of one second specified in [22] is assigned to each profile. The delay time specified here can be verified based on the studies on unbuckling- and reaction time required depending on the age of the subjects by McLean and Corbett [23, p. 9 ff.]. It is ensured that the earliest time for the first door passage is $12 \mathrm{~s}$. In this way, the reaction time of the crew and the time for opening the exits and inflating the emergency slides are considered [24]. The evacuation simulation starts with the unbuckling process and ends as soon as the last person has reached the ground. For validation, Table 4 shows average flow rates of emergency exits of commercial aircraft according to [25, p. 189]. For the simulations given here, only Type I and Type III emergency exits are relevant.

The model pertaining to the initial parameter configuration is used as a starting point for the parameter variation in the subsequent section. After 30 simulations, the initial parameter configuration achieves an average total evacuation time of $88.59 \mathrm{~s}$, with a standard deviation of $3.93 \mathrm{~s}$. Table 5 shows the achieved average flow rates of the respective emergency exits of the inertial reference model.

The achieved flow rates of the Over Wing Exits (TYPE III) are close to the reference values from Table 4, whereby 


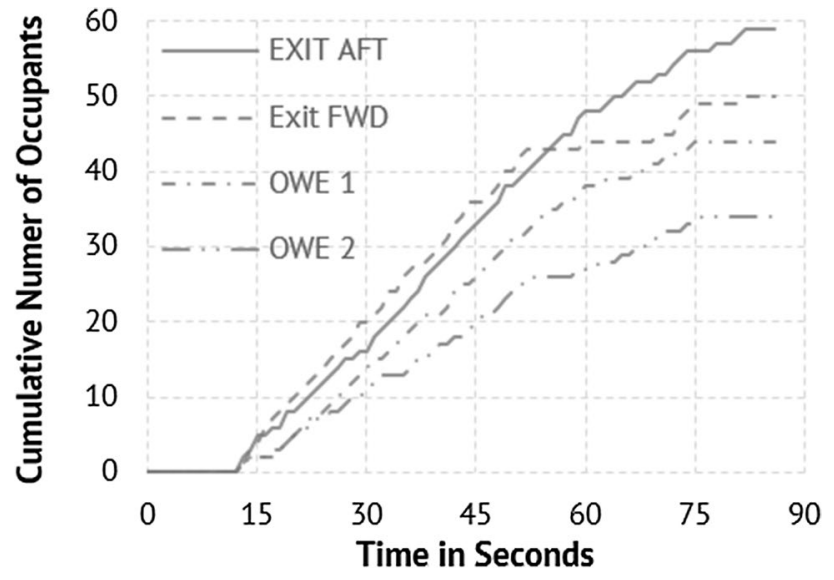

Fig. 6 Total number of occupants to use selected door

Over Wing Exit 2 (OWE 2) is slightly less frequented. The flow rate of the front exit shows a high correspondence with the reference value for a TYPE I emergency exit. On the other hand, the rear exit exceeds the reference value by $26 \%$, because the frequency is significantly higher than assumed in [25]. Figure 6 shows the cumulative door passages. It is evident that the two floor-level exits have an almost equal rate for the major part of the evacuation. The flow rate of the Over Wing Exits, by contrast, diverges visibly at an early point in time. The flow rates given above result from the gradients of the curves outlined below.

\section{Parameter variation}

The following section presents the findings of the respective parameter variation. The analysis of the sensitivities of the individual parameters based on the indicated influences of the respective body and behaviour parameters on the total evacuation time is discussed afterwards. All data are given in relation to the reference model described in Chapter 3. In order to ensure a high significance of the data, an analysis of the respective behaviour- and body parameters in each individual case is necessary. All data are the results of 30 randomized simulations for the respective parameter under examination.

\subsection{Body characteristics}

The analysis of the body characteristics and its influence on the evacuation time is based on the parameters, movement speed, acceleration time, speed on the emergency slide and the individual body dimensions of the occupants.
Table 6 Results of simulation with maximum movement speeds

\begin{tabular}{llll}
\hline Emergency exit & Door count & Flow rate & Time per exit \\
\hline Exit $_{\text {FWD }}$ & 45 & 0.735 PAX/s & $75.65 \mathrm{~s}$ \\
Owe 1 & 38 & 0.906 PAX/s & $67.15 \mathrm{~s}$ \\
Owe 2 & 42 & $0.828 P A X / \mathrm{s}$ & $67.15 \mathrm{~s}$ \\
Exit $_{\text {AFT }}$ & 60 & 0.965 PAX/s & $75.42 \mathrm{~s}$ \\
Evacuation time & $77.1 \mathrm{~s}$ & & \\
\hline
\end{tabular}

\subsubsection{Movement speed}

The analysis of the walking speed and its influence on the total evacuation time is performed using the average maximum walking speed according to Bohannon [21, p. 17] given in Table 3 . In order to ensure a high randomization of the age classes and the individual differences of the occupants, the respective profiles are assigned the standard deviations indicated in the table. Table 6 shows the average result of these 30 simulations. It is evident that the total evacuation time is reduced by $11 \mathrm{~s}$ in relation to the reference model.

\subsubsection{Acceleration time}

The influence of the acceleration time required for an occupant to reach its maximum speed of motion is shown in Fig. 7. The indicated times represent a variation of the acceleration times from $0.2 \mathrm{~s}$ to $0.75 \mathrm{~s}$. It demonstrates that an increased acceleration time results in a significant rise in the total evacuation time.

\subsubsection{Speed on emergency slide}

For the analysis of the influence of the sliding speed, which an occupant can reach on an emergency slide, a speed

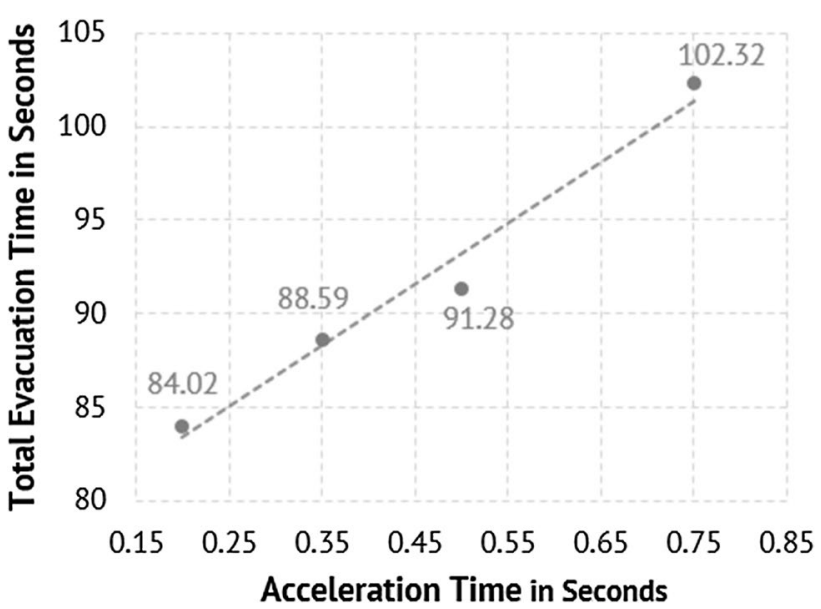

Fig. 7 Influence of the acceleration time on total evacuation time 


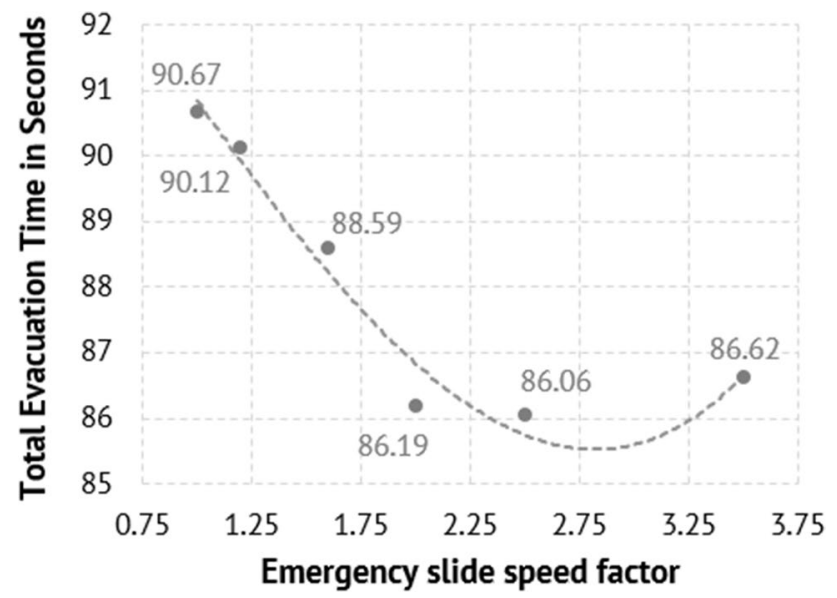

Fig. 8 Influence of the slipping speed on the total evacuation time

Table 7 Results of the simulation with changed body dimensions

\begin{tabular}{llll}
\hline Emergency exit & Door count & Flow rate & Time per exit \\
\hline Exit $_{\text {FWD }}$ & 48 & $0.785 \mathrm{PAX} / \mathrm{s}$ & $77.06 \mathrm{~s}$ \\
Owe 1 & 30 & $0.836 \mathrm{PAX} / \mathrm{s}$ & $68.19 \mathrm{~s}$ \\
Owe 2 & 44 & $0.877 \mathrm{PAX} / \mathrm{s}$ & $68.19 \mathrm{~s}$ \\
Exit $_{\text {AFT }}$ & 62 & $1.023 \mathrm{PAX} / \mathrm{s}$ & $75.66 \mathrm{~s}$ \\
Evacuation time & $77.06 \mathrm{~s}$ & & \\
\hline
\end{tabular}

variation is carried out. Starting from the speeds of the reference model, the speed on the emergency slide is successively increased from 100 to $350 \%$. The evacuation times resulting from the simulation are shown in Fig. 8. It is shown that an increase of the sliding speeds leads to a parabolic curve of the evacuation times with a minimum between 250 and 300\% compared to the reference model.

\subsubsection{Body dimensions}

The body dimensions specified in the reference model in relation to the shoulder width are unsuitable according to [25]. The use of waist circumference for different classes of age is justified by the design of a passenger cabin, since the minimum width in the escape route always represents the distance between the armrests of the installed rows of seats. An obstruction of the escape route at the height of the shoulders of an occupant can normally be ruled out. The simulation result obtained using the average waist circumferences given in $[25$, p. 190$]$ is given in Table 7 . In relation to the flow rates of the reference model shown Table 5 the frequency of door passages has increased significantly in part. The total evacuation time decreases by $14 \%$, which shows a significant influence of the body dimensions.
Table 8 Results of the simulation with effect of prioritisation

\begin{tabular}{llll}
\hline Emergency exit & Door count & Flow rate & Time per exit \\
\hline Exit $_{\text {FWD }}$ & 53 & $0.683 \mathrm{PAX} / \mathrm{s}$ & $92.83 \mathrm{~s}$ \\
Owe 1 & 40 & $0.564 \mathrm{PAX} / \mathrm{s}$ & $92.92 \mathrm{~s}$ \\
Owe 2 & 34 & $0.466 \mathrm{PAX} / \mathrm{s}$ & $92.92 \mathrm{~s}$ \\
Exit $_{\text {aFT }}$ & 59 & $0.744 \mathrm{PAX} / \mathrm{s}$ & $97.58 \mathrm{~s}$ \\
Evacuation time & $97.58 \mathrm{~s}$ & & \\
\hline
\end{tabular}

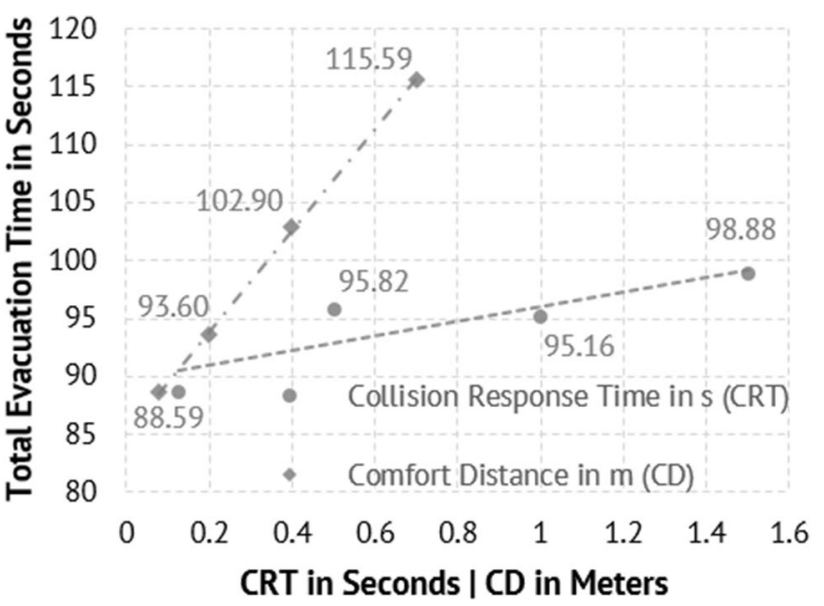

Fig. 9 Influence of collision response time and comfort distance on total evacuation time

\subsection{Conflict scenarios}

The influence of conflict situations and management on evacuation time is determined by variation parameters, such as comfort distance, collision response time, prioritisation and allocation of emergency exits. Panic and stress at the respective occupants can be simulated on the base of the mentioned parameters, whereby a realistic behaviour is represented.

\subsubsection{Prioritisation}

The priority-system implemented in PATHFINDER allows the simulation of crowding occupants. Thereby, several occupants are allocated a higher priority and other occupants are instructed to give priority to them. In the simulations performed, lower priority occupants are forced to avoid the aisles of the seat rows to allow higher priority occupants to pass. Table 8 shows the result of the simulation. Occupants with higher priority are granted a maximum priority time of $5 \mathrm{~s}$ in which they can move preferentially. The simulation results indicate a significant negative influence of the prioritisation on the evacuation time. Due to the strongly reduced flow rates, the total time increases to $97.58 \mathrm{~s}$. 


\subsubsection{Comfort distance}

In the simulation of the reference model, a comfort distance of $0.08 \mathrm{~m}$ is realized. This value represents the human behaviour during building evacuations and corresponds to a very dense crowd. In the parameter variation to the comfort distance, a successive increase of the distance up to $0.7 \mathrm{~m}$ is simulated. According to [26], this value is regarded as the average arm length of a European human being and corresponds to a pleasant conversation distance between persons. The influence of the comfort distance is shown in Fig. 9. It is clearly evident that it is impossible to evacuate a passenger cabin within $90 \mathrm{~s}$ by increasing the distance. Already a doubling of the initial comfort distance leads to an exceeding of the maximum acceptable total evacuation time. When reaching a distance equal to an average arm length of $0.7 \mathrm{~m}$, the resulting evacuation time exceeds the maximum requirement of $90 \mathrm{~s}$ by $30 \%$.

\subsubsection{Collision response time}

Since the proportion of older passengers is increasing due to demographic change and the human reaction time also increases with age, it must be demonstrated how important this influence is on evacuation time. In the simulation, changes in the collision response time from $0.175 \mathrm{~s}$ to $1.5 \mathrm{~s}$ are realized. The selected range represents the reaction times from competitive athletes up to older people. Within the simulation, this behaviour is represented by the time an occupant needs to react to a conflict situation. In this context, avoidance and evasion of obstacles in order to avoid collisions as well as the behaviour during periodization of groups of people are classified as conflicts. Figure 9 shows the influence of reaction time on evacuation time. It can be demonstrated that an increase in response time to $1.5 \mathrm{~s}$ leads to an increase in evacuation time by $11 \%$ compared to the reference model.

\subsubsection{Allocation of emergency exits}

According to EASA CS-25.812(e)(1), the path from each row of seats to the nearest emergency exit shall be marked in the flight direction and in the opposite direction [3]. As people do not make rational decisions in panic situations and therefore rarely pay attention to the marking of escape routes, the influence of this behaviour on the evacuation time has to be analysed. Assuming that people want to leave panic situations as quickly as possible and therefore try to find the nearest emergency exit, this behaviour can be simulated with a direct assignment of emergency exits. For this purpose, each occupant is deprived of the ability to change decisions during the simulation. As a consequence, every occupant must always reach the nearest emergency exit, no matter
Table 9 Results of the simulation with direct allocation of emergency exits

\begin{tabular}{llll}
\hline Emergency exit & Door count & Flow rate & Time per exit \\
\hline Exit $_{\text {FWD }}$ & 43 & $0.655 \mathrm{PAX} / \mathrm{s}$ & $82.64 \mathrm{~s}$ \\
Owe 1 & 47 & $0.652 \mathrm{PAX} / \mathrm{s}$ & $94.12 \mathrm{~s}$ \\
Owe 2 & 38 & $0.509 \mathrm{PAX} / \mathrm{s}$ & $94.12 \mathrm{~s}$ \\
Exit $_{\text {AFT }}$ & 56 & $0.917 \mathrm{PAX} / \mathrm{s}$ & $76.95 \mathrm{~s}$ \\
Evacuation time & $94.12 \mathrm{~s}$ & & \\
\hline
\end{tabular}

how long the waiting time is. The results of this simulation are listed in Table 9. Compared to the reference model, the EXIT $_{F W D}$ and EXIT ${ }_{A F T}$ are less frequented. The two Over Wing Exits, by contrast, have a significantly higher frequency. This leads to an $11 \mathrm{~s}$ higher evacuation time at both exits, which results in an increase of the total evacuation time of $6 \%$.

\section{Discussion}

The presented results of the parameter variation show a significant influence of the body and behaviour parameters on the evacuation time of passenger cabins. The analysis of the body characteristics shows that the respective parameters exhibit an opposite trend and partially compensate each other. The influence of movement speeds shown in Table 6 is in direct contrast to the acceleration time results shown in Fig. 7. Due to demographic change and the associated increase in the number of older passengers, it can be assumed that increasing acceleration times are plausible and must be taken into account in future simulations. This assumption is supported by the study of [27, p. 25]. Data on age-dependent walking speeds published there show the same trend. In particular, the data on the older experimental groups show a rapid decrease in the ability to move, which makes rapid evacuation increasingly difficult. Following the results of the study by Bohannon [21], which takes age-specific differences with regard to maximum average movement speeds into account, this also applies to these parameters. If the results of the parameter variation for the changed body dimensions from Table 7 are additionally considered, it can be wrongly deduced that the shown negative influence of the acceleration times can be compensated with respect to the evacuation times. In the underlying work of Y. Liu et al. [25, p. 191], the waist size is identified as the main influencing parameter on the evacuation time. However, the waist sizes reported there are too low for future studies with regard to the alarming trend of overweight young people. Taking into account the OECD study from 2017 [28] (Chapter 4) on the development of overweight young people, this compensation is not sustainable in the long 
term, as a steady increase in waist sizes must be assumed. The negative influences of body measurements on the overall evacuation process using the TYPE III Over Wing Exit given in [23] support this thesis. The analysis of the slide speeds demonstrates that the angle of the emergency slide has a significant influence on the evacuation time. The parabolic curve shown in Fig. 8 and the resulting increased evacuation times at higher speed factors result from the steeper angles and a reduced coefficient of friction of the emergency slides. The limiting factor here is the time required for the respective subjects to exit the emergency slide at ground level. The increased deceleration at the bottom of the emergency slide resulting from the higher speeds leads to increased waiting times at the top of the emergency slide. The results presented are coherent with the data from Motevalli et al. [29] (Appendix F). The mathematical approach formulated there for the design of emergency slides, taking into account the geometrical parameters as well as the friction coefficient, show a similar parabolic progression with respect to the slide velocities. The varying total evacuation times given in Fig. 8 are therefore conclusive and comprehensible.

The analysis of the conflict situations shows a clearly defined trend in comparison to the influence of the body characteristics. It can be seen that the individual characteristics of the occupants have a significant negative influence on the total evacuation time. The prioritization results, given in Table 8 , illustrate this trend. It is evident that irrational behaviour in stressful situations prevents an orderly evacuation. Since the simulation results only represent a priority time of $5 \mathrm{~s}$, it must be assumed that physically strong individuals with permanent jostling behaviour lead to an even more negative impact. This reasoning is consistent with the observations of D. Helbig et al. [30, p. 6] who found increasing physical interaction between people in his analyses of human behaviour in panic situations. In the study, it is indicated that with increasing stress levels there is increased jostling among the subjects.

The following statements can be deduced from the results of Fig. 9. First: With regard to the demographic change and the resulting passenger composition, it must be assumed that an evacuation of a passenger cabin within the prescribed $90 \mathrm{~s}$ will successively become more difficult in the coming decades. The increase in reaction time in particular will lead to a critical problem in evacuation situations in the long term. The age-related influence on reaction time has also been analysed by McLean and Corbett $[23$, p. $10 \mathrm{ff}$.$] . In their age-dependent reaction,$ times it can be seen that a tripling of the age leads to a doubling of the reaction times. The results given support the above conclusion and should also be considered in further analyses. Second:The analysis of comfort distance shows the greatest sensitivity of all parameter variations.
However, the results need to be considered in a more sophisticated way. It is plausible that the increased distance between the respective occupants results in a significantly increased evacuation time. However, it is questionable to which extent this reflects the real behaviour in panic situations. Due to the increased stress level and the human survival instinct, a crowded situation within the cabin must be assumed. It can be concluded that the results of the parameter variation for prioritization have a higher significance with respect to human behaviour. This argumentation is supported by the work of Helbing et al. [30]. The human behaviours in panic situations given there show a strong trend towards herding, resulting in dense crowding with abandonment of individual comfort preferences. An increase in the tendency to physical confrontation has already been described in the analysis of prioritization.

The result from Table 9 for the direct assignment of emergency exits shows that finding the nearest emergency exit does not improve the evacuation time. Compared to the reference model, the evacuation time increases by $6 \%$. In particular, the higher frequented Over Wing Exits and their geometric arrangement cause problems. Considering the OECD study [28] (Chapter 4) on the development of obesity and physical fitness in humans, it can be assumed that rapid evacuation via these exits will become more difficult in the future. In addition, the results from Table 9 show that the requirement stated in the certification regulation that there be a clear path marking at each row of seats to the nearest emergency exit [3] (Paragraph 25.812 (e) (1)) is not purposeful for narrow-body aircraft with Over Wing Exits. In order to avoid an accumulation and crowding of people in front of Over Wing Exits, an alternative guidance system must be considered for this purpose.

\section{Conclusion}

The study on emergency evacuation simulation of commercial aircraft shows that human behaviour can be modelled with agent-based simulation. It should be noted that due to demographic change and the resulting passenger mix, different behaviour can be expected in future evacuation situations. In particular, a person's individual body and behavioural parameters have a significant impact on evacuation time. The simulation software PATHFINDER used here provides sufficient parameters to represent a realistic human behaviour within the simulation environment. Through the specific variation of reaction times, movement speeds as well as the simulation of priorities, an age-appropriate simulation can be depicted. The parameter variations illustrate that there is a very high sensitivity 
between human behaviour and total evacuation time. The results of the variations show that evacuation within the 90 s prescribed by EASA [3] (Paragraph 25.803 (c)) becomes more difficult as demographics change and the physical characteristics of passengers change with them. From this, the following statements can be made. First: The passenger composition specified for the certification test must be adapted to the above-mentioned problem, or the legal requirement of $90 \mathrm{~s}$ must be reconsidered. Second: The certification tests to be performed by the manufacturer do not represent a real emergency evacuation situation due to the failure to trigger a survival instinct. Since such a situation must not occur with regard to the safety of the participants, the results of the certification tests have limited significance. It is questionable to what extent an evacuation carried out under real conditions within $90 \mathrm{~s}$ is possible. Recent aircraft accidents show that occupants do not make rational decisions in the event of evacuation and increasingly think of themselves and their hand luggage. Other occupants and their emergency situation are only of limited interest due to self-motivation. This shows that the paragraph of the certification rule mentioned in the introduction, regarding the possibility to replace the certification test with data from tests and analyses, is of great importance. Since the EASA does not specify which data must be taken into account, there is an urgent need for legislative action here. The influencing variables investigated in this study for representing human behaviour using agent-based simulation should therefore serve as an indicator for future investigations. It should be examined whether the approach used here can also be transferred to other aircraft and configurations. Especially the representation of non-rational decisions by means of agent-based simulation has to be analysed more deeply in order to provide a safe and resource-saving alternative to the certification test.

Funding Open Access funding enabled and organized by Projekt DEAL.

Availability of data and material Data can be made available on request.

\section{Compliance with ethical standards}

Conflict of interest On behalf of all authors, the corresponding author states that there is no conflict of interest.

Open Access This article is licensed under a Creative Commons Attribution 4.0 International License, which permits use, sharing, adaptation, distribution and reproduction in any medium or format, as long as you give appropriate credit to the original author(s) and the source, provide a link to the Creative Commons licence, and indicate if changes were made. The images or other third party material in this article are included in the article's Creative Commons licence, unless indicated otherwise in a credit line to the material. If material is not included in the article's Creative Commons licence and your intended use is not permitted by statutory regulation or exceeds the permitted use, you will need to obtain permission directly from the copyright holder. To view a copy of this licence, visit http://creativecommons. org/licenses/by/4.0/.

\section{References}

1. Allianz Global Corporate \& Specialty SE (2014) Global Aviation Safety Study, A review of 60 years of improvements in aviation safety. Allianz Global Corporate \& Specialty SE, Munich, Germany. https://www.agcs.allianz.com/news-and-insights/ reports/global-aviation-safety-study.html. Accessed 23 Jan 2021

2. Coalition for Airport and Airplane Passenger Safety (1999) Surviving the crash, the need to improve lifesaving measures at our nation's airport. CAAPS, Washington DC. http://www. disastersrus.org/emtools/aircrash/iaffrpt.pdf. Accessed 23 Jan 2021

3. Agency EAS (2019) Certification specifications and acceptable means of compliance for large aeroplanes CS-25-Amendment 23. EASA, Cologne. https://www.easa.europa.eu/docum ent-library/certification-specifications/cs-25-amendment-23. Accessed 23 Jan 2021

4. Office of Technology Assessment Congress of the United States (1993) Aircraft Evacuation testing: Research and Technology Issues. OTA, USA. https://ota.fas.org/reports/9306.pdf. Accessed 23 Jan 2021

5. Kirchner A, Klüpfel H, Nishinari K, Schreckenberg M (2003) Simulation of competitive egress behavior: comparison with aircraft evacuation data. Physica A Statistical Mech Appl 324:689-697. https://doi.org/10.1016/S0378-4371(03)00076-1

6. Togher M, Al Barghuthi NB (2018) A review of aircraft evacuation models and behavioural simulations. In: 2018 Fifth HCT Information Technology Trends (ITT) Dubai, United Arab Emirates, pp 276-280. https://doi.org/10.1109/CTIT.2018.8649500

7. Miyoshi T, Nakayasu H, Ueno Y, Patterson P (2012) An emergency aircraft evacuation simulation considering passenger emotions. Comput Ind Eng 62:746-754. https://doi.org/10.1016/j.cie.2011. 11.012

8. Galea E, Lawrence P, Gwynne S, Filippidis L, Blackshields D, Cooney D (2015) buildingEXODUS V5.0 Technical Manuel and User Guide. University of Greenwich Centre for Numerical Modelling \& Process Analysis, London. https://gala.gre.ac.uk/ id/eprint/15470/. Accessed 23 Jan 2021

9. Mott MacDonald Simulation Group (2014) Simulation of transient evacuation and pedestrian movement, STEPS User Manual v5.3. Mott MacDonald Simulation Group, London

10. Engineering $T$ (2020) Pathfinder technical reference manual. Thunderhead Engineering, Manhattan. https://files.thunderhea deng.com/support/documents/pathfinder-technical-referencemanual-2020-5.pdf. Accessed 23 Jan 2021

11. Cuesta A, Ronchi E, Geynne S (2015) Collection and use of data from school egress trials. In: Human Behaviour in Fire: 6th international symposium, pp 233-244

12. Galea E, Blake SJ, Lawrence P, Gwynne S (2003) The airEXODUS evacuation model and its application to aircraft safety. Fire Safety Survivabil No. RTO-MP-103

13. Engineering $T$ (2019) Pathfinder, User Manual. Thunderhead Engineering, Manhattan. https://files.thunderheadeng.com/ 
support/documents/pathfinder-usermanual-2020-5.pdf. Accessed 23 Jan 2021

14. Hart P, Nilsson N, Raphael B (1968) A formal basis for the heuristic determination of minimum cost paths. IEEE Trans Syst Sci Cybern 4:100-107. https://doi.org/10.1109/TSSC.1968.300136

15. Helmreich M, Prokop S, Schwemmer C (2005) "Algorithmen zur Pfadplanung", Lehrstuhl für Informatik 12. Universität Erlangen, Erlangen. https://www12.informatik.uni-erlangen.de/edu/rober tino/ausarbeitung.pdf. Accessed 23 Jan 2021

16. Johnson $G$ (2006) Smoothing a navigation mesh path. In: Rabin S (ed) Al Game Programming Wisdom, vol 3. Charles River Media, Newton, pp 129-139

17. Amor HB, Murray J, Obst O (2003) Fast, neat and under control: inverse steering behaviors for physical autonomous agents. Universität Koblenz-Lindau, Koblenz, Germany, Institut für Informatik. http://citeseerx.ist.psu.edu/viewdoc/summary?doi=10.1.1. 513.7552. Accessed 23 Jan 2021

18. Schneider B (2011) Die Simulation menschlichen panikverhaltens: ein agenten-basierter ansatz. Springer, Wiesbaden

19. Roscher S (2020) Evakuierungssimulation eines Zweideckflugzeuges: Analyse menschlichen Verhaltens mithilfe agentenbasierter Algorithmen. Technische Universität Berlin, Berlin, Germany, Fachgebiet Luftfahrzeugbau und Leichtbau

20. Hedo JM, Martinez V (2010) Computer model for numerical simulation of emergency evacuation of transport aeroplanes. Aeronaut J 114:737-746. https://doi.org/10.1017/S000192400 000422X

21. Bohannon RW (1997) Comfortable and maximum walking speed of adults aged 20-79 years: reference values and determinants. Age and Aggeing 26:15-19. https://doi.org/10.1093/ageing/ 26.1.15

22. Fritsche F (2017) Ein Beitrag zur Simulation der Notevakuierung von Flugzeugkabinen. Technische Universität Berlin, Berlin, Germany, Fachgebiet Luftfahrzeugbau und Leichtbau

23. McLean GA, Corbett CL (2004) Access-to-egress III: repeated measurement of factors that control the emergency evacuation of passengers through the transport airplane type-III Overwing Exit. Office of Aerospace Medicine, Washington DC. https:// rosap.ntl.bts.gov/view/dot/40484. Accessed 23 Jan 2021

24. Dzikus N, Berens M (2005) Numerische simulation der passagierevakuierung aus wide-body flugzeugen mit lower deck seating compartments. Technische Universität Berlin, Berlin, Germany, Fachgebiet Luftfahrzeugbau und Leichtbau

25. Liu Y, Wang W, Huang H-Z (2014) A new simulation model for assessing aircraft emergency evacuation considering passenger physical characteristics. Reliab Eng Syst Safety 121:187-197. https://doi.org/10.1016/j.ress.2013.09.001

26. DIN Deutsches Institut für Normung e.V. (2005) DIN 33402-2, Ergonomie - Körpermße des Menschen - Teil 2: Werte," Beuth Verlag GmbH, Berlin, Germany. https://doi.org/10.31030/31703 86

27. Bosnia E, Weidmann U (2017) Estimating pedestrian speed using aggregated literature data. Phys A 468:1-29. https://doi.org/10. 1016/j.physa.2016.09.044

28. Indicators OECD (2017) Health at a glance 2017. OECD Publishing, Paris. https://doi.org/10.1787/19991312

29. Motevalli V, Monajemi L, Rassi M (2008) Evaluation and mitigation of aircraft slide evacuation injuries. The National Academies Press, Washington DC. https://doi.org/10.17226/23103

30. Helbing D, Farkas I, Molnar P (2002) Simulation of pedestrian crowds in normal and evacuation situations. Institut für wirtschaft und Verkehr, Technische Universität Dresden, Dresden, Germany

Publisher's Note Springer Nature remains neutral with regard to jurisdictional claims in published maps and institutional affiliations. 